\title{
A COMPARISON OF RESEARCH-ORIENTED PROJECTS IN UNDERGRADUATE INFORMATION TECHNOLOGY COURSES
}

\author{
George Stefanek, Purdue University Northwest, stefanek@pnw.edu
}

\begin{abstract}
Undergraduate information technology courses often require students to complete software projects that are similar to real-world-like projects, but can also be topics that contribute to on-going research projects at the university. This study looks at the use of three different research-oriented topics from a single faculty research-project that were integrated into three different information technology courses. The research attempts to see if the differences between the topics have an effect on student perceived usefulness of these topics as compared to actual real-world projects, if these projects stimulated their interest into research, enhanced their undergraduate experience, increased their programming skills, and increased their motivation to attend graduate school.
\end{abstract}

Keywords: Affinity Group Model, Research-Oriented Courses, Undergrad Research, IT Education

\section{INTRODUCTION}

Undergraduate information technology courses often require students to complete software projects that are similar to real-world-like projects, but can also be topics that contribute to on-going research projects at the university. Even though undergraduate students may not be prepared to adequately perform research-related activities that directly support these type of research projects, they can participate in some narrow aspect of the research that does not require extensive experience and matches their skill sets. Introducing students to research-oriented projects where they can make some contribution to the research would expose students to research techniques, new technologies, and the integration of technologies to solve problems in new and innovative ways. If a research project technology, course requirements and student skill sets align, then the research topic may be incorporated into a course. Stefanek (Stefanek \& Desai, 2018) has studied the perceived effectiveness by students of the use of research-oriented projects to increase student interest in research, enhance the student undergraduate experience, increase student programming skills and motivate students to continue their education beyond the undergraduate level.

This paper describes three different research topics used in three separate information technology courses and compares student perspectives via a survey. The research attempts to see if the differences between the topics have an effect on student perceived usefulness of these topics as compared to actual real-world projects, if these projects stimulated their interest into research, enhanced their undergraduate experience, increased their programming skills, and increased their motivation to attend graduate school. Additionally, student grades on the three research-oriented projects were compared against each other and the survey results to determine if there was any correlation between high grades and positive responses in the survey. The research was done to determine the sensitivity of student support of the research topics as compared to the level of complexity of the research project and its match to the student skill set.

\section{BACKGROUND}

Elton (Elton, 2016) described teaching with research by undergraduates as an approach to bring research into a course. He indicated that it can be very successful in the final year of a student in the form of project work, but should not be the basis for whole courses. He described a program at a major research university that attempted to introduce undergraduate research at the beginning of undergraduate education that ultimately proved to be a failure because students were not able to handle the research topics.

Hathaway, Nagda, and Gregerman (Hathaway, Nagda \& Gregerman, 2002) have investigated the relationship between undergraduate participation in research activities and continuing education at the graduate level. The program focused 
on successful faculty-student collaboration in research where students participated in a faculty research project for 1012 hours per week. It was found that found that participation in undergraduate education gains participants a deeper understanding of their field of study, increased critical thinking and communication skills and increased their decision to go to graduate school.

Gates, Teller, Bernat, Delgado and Kubo Della-Piana (Gates et. al., 1999) have investigated the use of the Systems and Software Engineering Affinity Research Group model at the University of Texas at El Paso to provide a socialization mechanism and infrastructure to help engage a larger pool of undergraduate students at various years in their undergraduate education into research projects. This model integrated students into small research groups that supported a larger research project and used structured activities to develop student technical, research and group skills.

Russell, Hancock and McCullough (Russell, Hancock \& McCullough, 2007) conducted a nationwide evaluation of undergraduate research opportunities and found that these opportunities increase understanding, confidence, and awareness. It was found that $83 \%$ of the respondents reported that their confidence in their research skills increased and $73 \%$ indicated their awareness of what graduate school is like also increased. It was also found that participation in undergraduate research increased their anticipation of a Ph.D.

Fechheimer, Webber, and Kleiber (Fechheimer, Webber \& Kleiber, 2011) at the University of Georgia found that participation in undergraduate research for more than one semester correlated with an increase in student GPA.

Schneider et. al. (Schneider et. al., 2016) have found that having a pre-research course increased student involvement in research and benefited student research skills which indirectly benefited faculty research and made the students more prepared for research.

Varde (Varde, 2005) developed an undergraduate research program in the mechanical engineering department at the University of Michigan-Dearborn focused on energy and engine research. It was found that generally, students learned a great deal from the research project, including technical report writing, presentation skills and evaluation of data leading that lead to conclusions. It was found that over $40 \%$ of the students were planning to continue their education to the graduate level and students stated that their participation in the program motivated them to pursue an advanced degree or a career in R\&D.

Kuh (Kuh, 2008) has found that one of the key impact areas to enhance student engagement and increase student success is undergraduate research. He has found that many colleges and universities are now providing undergraduate research experiences for their students in all disciplines with the goal is to involve students with cutting-edge technologies to enhance the excitement that comes from solving important problems.

This background suggests that integrating research topics can be done with likely positive outcomes, but care must be taken to pick research-related topics which can be handled by undergraduates and that the introduction of research into teaching should probably be done further on in the curriculum and not with freshman courses. Topics need to be carefully chosen to match student skill levels.

\section{STATEMENT OF THE PROBLEM}

The effect of a specific research topic may have a positive or negative effect on a student's perceived benefit of doing such a research topic as related to student interest in research, enhancement of the undergraduate experience, increase in their programming skills, and motivation to continue their education to graduate school.

This study explores the differences between specific research projects and whether the projects had an effect on student responses to a survey on the effectiveness of using these research-oriented projects in computer information technology in order to help meet the following goals: 1) increase student interest in research, 2) enhance the student undergraduate experience, 3 ) increase student programming skills and 4) motivate students to continue their education beyond the undergraduate level. 


\section{OVERARCHING RESEARCH QUESTIONS}

Stefanek (Stefanek \& Desai, 2018) has identified a number of research questions that are asked in a study survey to answer the above goals:

1) Did the research-oriented project topic increase their level of programming skills specific to the course?

2) Did the research-oriented project topic increase their level of programming skills more than other types of programming projects?

3) Do students prefer a research-oriented project topic to other topics?

4) Do students prefer to have projects that contribute to a professor's on-going research?

5) Would students like to have other research-oriented topics in other courses?

6) As a result of doing a research-oriented topic in the course, would students like the opportunity to collaborate on an undergraduate information technology research project with a professor?

7) As a result of having exposure to a research-oriented topic in the course project, would students be motivated to go to graduate school?

8) As a result of having exposure to a research-oriented course topic, would students like the opportunity to do more undergraduate research through independent study courses?

9) Do students perceive that having some undergraduate research-oriented experience have a positive impact on getting a job after graduation?

10) Did doing a research-oriented project in the course enhance a student's undergraduate experience?

Specifically, the questions that correlated to the above goals 1 through 4 are as follows: Goal 1: (Survey Questions 3, 4, 5, 6, 8), Goal 2: (Survey Questions 9, 10), Goal 3: (Survey Questions 1, 2), Goal 4: (Survey Question 7).

\section{STUDY METHODS AND DATA COLLECTION}

\section{Participants}

In order to explore the differences between research projects on student perceived effectiveness of using such researchoriented course projects as an approach for increasing student interest in research, increasing student motivation and continuing their education beyond the undergraduate level, a study was conducted where students were evaluated using this approach. The study was conducted in three courses with similar course content and taught by the same professor. The end-of-semester course projects in each of the three courses used three different research-oriented projects. There were a total of 42 students that participated in the study over the course of two years. Course details are shown in Table 1.

Table 1. Study Course Descriptions

\begin{tabular}{|c|c|c|c|c|c|}
\hline Course & Session & Year & Department $^{1}$ & Major $^{2}$ & $\begin{array}{l}\text { Number of Students / } \\
\text { Survey Respondents }\end{array}$ \\
\hline $\begin{array}{c}\text { CNIT } 350 \\
\text { Object Oriented } \\
\text { Programming } \\
\end{array}$ & Spring & 2017 & CITG $^{3}$ & CIT $^{4}$ & $17 / 14$ \\
\hline $\begin{array}{c}\text { ITS } 245 \\
\text { Integrative } \\
\text { Programming }\end{array}$ & Fall & 2017 & CITG & CIT & $11 / 7$ \\
\hline $\begin{array}{c}\text { ITS } 340 \\
\text { Advanced } \\
\text { Programming }\end{array}$ & Spring & 2018 & CITG & CIT & $14 / 12$ \\
\hline
\end{tabular}

1: This refers to the department within the College of Technology that offered the concerned course

2: This refers to the major of the students that participated in the study by enrolling in the offered course

3: $\mathrm{CITG}=$ Computer Information Technology and Graphics

4: $\mathrm{CIT}=$ Computer Information Technology 


\section{Data Collection Methods}

The data that was collected included: 1) survey-based feedback from the students that participated in the study, and 2 ) end-of-semester project grades from classes that used research-oriented projects. The survey was used to gauge student interest in research, whether the research-oriented project enhanced the student's undergraduate experience, whether it increased their programming skills and whether it motivated them to possibly continue their education beyond the undergraduate level. The end-of-semester grades were used to determine if there were differences in difficulty between the projects as reflected by grades for the project and if these differences correlated to student responses in the survey. The survey results are found in Tables $2 \mathrm{a}-\mathrm{c}$ and the scores for research-oriented projects are in Table 3.

\section{Procedure}

This section summarizes earlier work done by Stefanek (Stefanek \& Desai, 2018). The section focuses on the methodology used to conduct the research-oriented projects. The process involved the following steps:

1. Select a research-oriented topic for the class project. A research-oriented topic is selected from an on-going faculty research project. If a sub-topic can be chosen from the research project that matches the skill sets of the students doing a project in the course, and the topic is within the scope of the course content, then it can be used as a course project topic. See the next section for a description of the projects.

2. A Statement of Work (SOW) is written by the professor with the research project in conjunction with the class instructor to identify the topic, project scope for the course project, and to make sure that the topic correlates to the course content and student skill sets as discussed in step 1.

3. The class project is done in teams of 2-3 students.

4. The student teams clarify any questions in the SOW prior to starting the project.

5. At the completion of the course projects, each team demonstrates their project application to the class.

6. The student team project is scored by the instructor in the class according to a rubric designed by the course instructor that correlates to the SOW. All the requirements specified in the statement of work are scored on whether they were implemented by the student team and how well they worked. A score between 0 and 100 is assigned to the project.

7. At the completion of the projects by all the student groups in the course, the professor with the research project (in the study the professor with the research and the class instructor were the same) would evaluate whether any of the student projects were of a high enough quality to be integrated into the research project.

\section{Description of the Research-Oriented Projects}

There were three different research-oriented projects in the three courses CNIT 350-Object-Oriented Programming, ITS 245-Integrative Programming, and ITS 340-Advanced Programming. The three courses had similar content where CNIT 350 and ITS 340 were object-oriented programming courses using Java, but the ITS 340 course emphasized data structures. The ITS 245 Integrative Programming course taught object oriented programming using C\#. Each of the courses required a project to be completed by a student team. The students in the study courses were learning either C\# or Java programming and had taken at least one course in database systems. Therefore, the topics that were chosen had to match the student skill sets and the course content. Each of the projects was derived from an on-going faculty research project entitled “A Natural Language Driven Intelligent Home Health Status Monitor and Advisor".

ITS 340 - Integrative Programming Project Description: This research project included data on a patient's general medical history collected through an automated interview with the patient. The interview had to use a data structure to drive the interview. The input data from the interview was stored in a back-end relational database system in the general medical history tables. The input to the interview questions used a graphical user-interface built using Java Swing. There was also a need to create a user-friendly, graphical user interface to the database's general medical history tables that would allow a user to view, modify, add and delete the collected general medical history data. The skill sets required for this research-oriented project were object-oriented design, Java, Java Swing programming, database programming, database design, and data structures. All these skill sets that the students had were either learned in previous courses or within this course and therefore matched the required skill set for the research-oriented project. The level of code complexity was more difficult in this research-oriented project, but there were less graphical 
forms that needed to be created. There were Java classes that created a connection to the back-end database system, read data from tables, updated data in tables, and inserted data into tables.

ITS 245 - Integrative Programming Project Description: This research project included creating a C\# graphical user interface to database tables for patient demographics, vital signs, allergy history, family history, illness history, immunization history, and medications. The graphical user interface would be built using native C\# tabbed forms for each of these areas. The user would select a patient and then can view a patient's data in each of these areas. Also, the data could be edited, undone, and records could be added and deleted. A report function would create a report with all the general medical history data. The level of code complexity was more moderate in this research-oriented project, but there was extensive coding for all the required graphical forms that needed to be created. Code was also needed to read and write records to database tables within the $\mathrm{C} \#$ classes.

CNIT 350 - Object Oriented Programming Project Description: This research project included creating a Java graphical user interface to database tables for patient demographics, vital signs, allergy history, family history, general medical history, illness history, immunization history, past pregnancies, therapy history, and medications. The graphical user interface would be built using Java Swing tabbed panels for each of these areas. The user would select a patient and then can view a patient's data in each of these areas. The forms had to be modal in that the entry fields would be blocked and greyed until an edit or add button would be clicked to unlock the entry areas. Upon save the mode would switch back where the fields were locked. Also, the data could be edited, undone, and records could be added and deleted. A report function would create a report with all the general medical history data.

\section{RESULTS}

A total of 42 students participated in the study over the course of two years. There were a total of 33 students that completed the anonymous, hard-copy survey that was distributed to all the students in the study. The survey used a Likert scale of 1-5 where 5 was "Strongly Agree", 4 was "Agree', 3 was "Neutral", 2 was "Disagree" and 1 was "Strongly Disagree". Tables 2a-c present the participant's responses to each question in the survey. Each table has responses from each class. It quantifies the survey results by displaying both the number of students that provided answers to each of the scoring categories as well as the percentage of the total number of participating students that responded in each of the aforementioned ways. Scores for the team projects were assigned to all 42 students. Table 3 presents the grade scores for each of the projects in the courses.

Table 2a. Survey Results in CNIT 350 Course (Total Number of Respondents N=14)

\begin{tabular}{|c|c|c|c|c|c|c|c|c|}
\hline $\mathrm{Q}^{1}$ & $\begin{array}{c}\text { StronglyA } \\
\text { gree }^{2}\end{array}$ & Agree $^{3}$ & Neutral $^{4}$ & Disagree $^{5}$ & $\begin{array}{c}\text { Strongly } \\
\text { Disagree }^{6}\end{array}$ & $\%(+)^{7}$ & $\begin{array}{c}\% \\
(-)^{8} \\
\end{array}$ & $\%$ (neutral) ${ }^{9}$ \\
\hline 1 & 7 & 7 & 0 & 0 & 0 & 100 & 0 & 0 \\
\hline 2 & 7 & 6 & 1 & 0 & 0 & 92.9 & 0 & 7.1 \\
\hline 3 & 3 & 4 & 4 & 3 & 0 & 50.0 & 21.4 & 28.6 \\
\hline 4 & 3 & 10 & 1 & 0 & 0 & 92.9 & 0 & 7.1 \\
\hline 5 & 7 & 3 & 3 & 1 & 0 & 71.4 & 7.1 & 21.4 \\
\hline 6 & 4 & 7 & 3 & 0 & 0 & 78.6 & 0 & 21.4 \\
\hline 7 & 0 & 3 & 8 & 1 & 2 & 21.4 & 21.4 & 57.1 \\
\hline 8 & 2 & 6 & 6 & 0 & 0 & 57.1 & 0 & 42.9 \\
\hline 9 & 4 & 10 & 0 & 0 & 0 & 100.0 & 0 & 0 \\
\hline 10 & 5 & 9 & 0 & 0 & 0 & 100.0 & 0 & 0 \\
\hline $\operatorname{Avg}^{10}$ & 4.2 & 6.5 & 2.6 & 0.5 & 0 & 76.4 & 5 & 18.6 \\
\hline
\end{tabular}

1: Q: Question from survey (see Appendix A)

2: Total number of students that provided feedback of "Strongly Agree"

3: Total number of students that provided feedback of "Agree"

4: Total number of students that provided feedback of "Neutral"

5: Total number of students that provided feedback of "Disagree"

6: Total number of students that provided feedback of "Strongly Disagree" 


\section{Issues in Information Systems}

Volume 19, Issue 4, pp. 53-64, 2018

7: $\%(+)$ : Positive feedback expressed as a percentage (rounded up) of the total number of students that responded to the survey as either "Strongly Agree" or "Agree"

8: \% (-): Negative feedback expressed as a percentage (rounded up) of the total number of students that responded to the survey as either "Strongly Disagree" or "Disagree"

9: \% (neutral): Neutral feedback expressed as a percentage (rounded up) of the total number of students that responded to the survey as "Neutral"

10: Avg: Average of all 10 questions.

Table 2b. Survey Results in ITS 245 Course (Total Number of Respondents N=7)

\begin{tabular}{|c|c|c|c|c|c|c|c|c|}
\hline $\mathrm{Q}^{1}$ & $\begin{array}{c}\text { StronglyA } \\
\text { gree }^{2}\end{array}$ & Agree $^{3}$ & Neutral $^{4}$ & Disagree $^{5}$ & $\begin{array}{c}\text { Strongly } \\
\text { Disagree }^{6}\end{array}$ & $\%(+)^{7}$ & $\begin{array}{l}\% \\
(-)^{8}\end{array}$ & $\%{\text { (neutral })^{9}}^{9}$ \\
\hline 1 & 0 & 4 & 3 & 0 & 0 & 57.1 & 0 & 42.9 \\
\hline 2 & 0 & 1 & 6 & 0 & 0 & 14.3 & 0 & 85.7 \\
\hline 3 & 0 & 1 & 2 & 3 & 1 & 14.3 & 57.1 & 28.6 \\
\hline 4 & 1 & 3 & 2 & 1 & 0 & 57.1 & 14.3 & 28.6 \\
\hline 5 & 1 & 2 & 1 & 3 & 0 & 42.9 & 42.9 & 14.3 \\
\hline 6 & 1 & 1 & 3 & 2 & 0 & 28.6 & 28.6 & 42.9 \\
\hline 7 & 1 & 0 & 3 & 1 & 2 & 14.3 & 42.9 & 42.9 \\
\hline 8 & 1 & 1 & 2 & 1 & 1 & 28.6 & 28.6 & 28.6 \\
\hline 9 & 1 & 4 & 3 & 0 & 0 & 71.4 & 0 & 42.9 \\
\hline 10 & 1 & 2 & 3 & 1 & 0 & 42.9 & 14.3 & 42.9 \\
\hline $\operatorname{Avg}^{10}$ & 0.7 & 1.9 & 2.8 & 1.2 & 0.4 & 37.2 & 22.9 & 40.0 \\
\hline
\end{tabular}

Table 2c. Survey Results in ITS 340 Course (Total Number of Respondents N=12)

\begin{tabular}{|c|c|c|c|c|c|c|c|c|}
\hline $\mathrm{Q}^{1}$ & $\begin{array}{c}\text { StronglyA } \\
\text { gree }^{2}\end{array}$ & Agree $^{3}$ & Neutral $^{4}$ & Disagree $^{5}$ & $\begin{array}{c}\text { Strongly } \\
\text { Disagree }^{6}\end{array}$ & $\%(+)^{7}$ & $\begin{array}{c}\% \\
(-)^{8}\end{array}$ & $\%$ (neutral) ${ }^{9}$ \\
\hline 1 & 3 & 7 & 2 & 0 & 0 & 83.3 & 0 & 16.7 \\
\hline 2 & 2 & 3 & 7 & 0 & 0 & 41.7 & 0 & 58.3 \\
\hline 3 & 1 & 3 & 3 & 4 & 1 & 33.3 & 41.7 & 25.0 \\
\hline 4 & 1 & 4 & 7 & 0 & 0 & 41.7 & 0 & 58.3 \\
\hline 5 & 1 & 3 & 7 & 1 & 0 & 33.3 & 8.3 & 58.3 \\
\hline 6 & 2 & 3 & 5 & 2 & 0 & 41.7 & 16.7 & 41.7 \\
\hline 7 & 0 & 1 & 6 & 3 & 0 & 8.3 & 25.0 & 50.0 \\
\hline 8 & 1 & 1 & 7 & 3 & 0 & 16.7 & 25.0 & 58.3 \\
\hline 9 & 1 & 8 & 2 & 0 & 0 & 75.0 & 0 & 16.7 \\
\hline 10 & 1 & 5 & 5 & 1 & 0 & 50.0 & 8.3 & 41.7 \\
\hline $\operatorname{Avg}^{10}$ & 1.3 & 3.8 & 5.1 & 1.4 & 0.1 & 42.5 & 12.5 & 42.5 \\
\hline
\end{tabular}

Table 3. Project Scores for Research-Oriented Projects

\begin{tabular}{|c|c|c|c|}
\hline Student & Course & Session/Year & Total Score (\%) \\
\hline 1 & CNIT 350 & Spring / 2017 & 90 \\
\hline 2 & CNIT 350 & Spring / 2017 & 85 \\
\hline 3 & CNIT 350 & Spring / 2017 & 90 \\
\hline 4 & CNIT 350 & Spring / 2017 & 50 \\
\hline 5 & CNIT 350 & Spring / 2017 & 89 \\
\hline 6 & CNIT 350 & Spring / 2017 & 50 \\
\hline 7 & CNIT 350 & Spring / 2017 & $101^{* *}$ \\
\hline 8 & CNIT 350 & Spring / 2017 & 89 \\
\hline 9 & CNIT 350 & Spring / 2017 & 50 \\
\hline 10 & CNIT 350 & Spring / 2017 & 90 \\
\hline 11 & CNIT 350 & Spring / 2017 & 90 \\
\hline 12 & CNIT 350 & Spring / 2017 & \\
\hline
\end{tabular}


Issues in Information Systems

Volume 19, Issue 4, pp. 53-64, 2018

\begin{tabular}{|c|c|c|c|}
\hline 13 & CNIT 350 & Spring / 2017 & $101^{* *}$ \\
\hline 14 & CNIT 350 & Spring / 2017 & $101^{* *}$ \\
\hline 15 & CNIT 350 & Spring / 2017 & 80 \\
\hline 16 & CNIT 350 & Spring / 2017 & 80 \\
\hline 17 & CNIT 350 & Spring / 2017 & 89 \\
\hline $\begin{array}{c}\text { Avg } \\
\text { CNIT 350 }\end{array}$ & & & 82.4 \\
\hline 18 & ITS 245 & Fall / 2017 & 80 \\
\hline 19 & ITS 245 & Fall / 2017 & 50 \\
\hline 20 & ITS 245 & Fall / 2017 & 80 \\
\hline 21 & ITS 245 & Fall / 2017 & 80 \\
\hline 22 & ITS 245 & Fall / 2017 & 95 \\
\hline 23 & ITS 245 & Fall / 2017 & 95 \\
\hline 24 & ITS 245 & Fall / 2017 & 95 \\
\hline 25 & ITS 245 & Fall / 2017 & 50 \\
\hline 26 & ITS 245 & Fall / 2017 & 80 \\
\hline 27 & ITS 245 & Fall / 2017 & 0 \\
\hline 28 & ITS 245 & Fall / 2017 & 50 \\
\hline $\begin{array}{c}\text { Avg } \\
\text { ITS 245 }\end{array}$ & & & $75.5^{*}$ \\
\hline 29 & ITS 340 & Spring / 2018 & 95 \\
\hline 30 & ITS 340 & Spring / 2018 & 95 \\
\hline 31 & ITS 340 & Spring / 2018 & 95 \\
\hline 32 & ITS 340 & Spring / 2018 & 95 \\
\hline 33 & ITS 340 & Spring / 2018 & 95 \\
\hline 34 & ITS 340 & Spring / 2018 & 92 \\
\hline 35 & ITS 340 & Spring / 2018 & 92 \\
\hline 36 & ITS 340 & Spring / 2018 & 95 \\
\hline 37 & ITS 340 & Spring / 2018 & 97 \\
\hline 38 & ITS 340 & Spring / 2018 & 95 \\
\hline 39 & ITS 340 & Spring / 2018 & 97 \\
\hline 40 & ITS 340 & Spring / 2018 & 97 \\
\hline 41 & ITS 340 & Spring / 2018 & 92 \\
\hline 42 & ITS 340 & Spring / 2018 & 95 \\
\hline $\begin{array}{c}\text { Avg } \\
\text { ITS 340 }\end{array}$ & & & 94.8 \\
\hline
\end{tabular}

* Row 27 omitted in calculation because it was for a student that did not turn in anything.

** Scores of 101 reflect extra points for completing an extra credit task.

\section{INTERPRETATION OF DATA}

Given, the small number of students involved in the study, a statistical analysis was not performed. The survey feedback showed that generally, there were differences to the survey responses based on the research-oriented project that was done. For CNIT 350 - Object Oriented Programming over 50\% of the students responded favorably to 9 out of the 10 questions and $90 \%$ of the students responded favorably to 5 of 10 questions (see column 7 in Table 2 a). In one question $57.1 \%$ of the respondents responded neutrally (see column 9 in Table 2a). In ITS 245 - Integrative Programming $50 \%$ of the students responded favorably to only 3 out of the 10 questions and over $40 \%$ of the students responded neutrally to 7 out of the 10 questions on the survey (see column 9 in Table 2b). In ITS 340 - Advanced Programming 3 students responded favorably to 3 out of the 10 questions and over $40 \%$ of the student responded neutrally to 8 out of the 10 questions on the survey (see column 7 in Table 2c).

Based on the above discussion, it can be seen that a majority of students in only one of the courses (CNIT 350) responded positively to the use of research-oriented projects in their course. This seems to imply that there were 
differences in student response to the questionnaire when a particular research-oriented project was used. The research-oriented projects in CNIT 350 - Object Oriented Programming and ITS 245 - Integrative programming had very similar projects in that both courses were required to implement a graphical user interface to tables in a database. CNIT 350 - Object Oriented Programming used Java to implement the user-interface and database code and in ITS 245 - Integrative Programming the C\# programming language was used. Both interfaces used native-based forms for designing the interface forms and both courses had the same requirements of what had to be implemented in the userinterfaces. The database code had similar code that had to be written to establish a connection to the back-end database and then used embedded SQL to implement the select, update, insert and delete commands. Finally, in the ITS 340 course $42.5 \%$ of the students responded favorably to the use of a research-oriented topic and $42.5 \%$ were neutral. Only $12.5 \%$ responded unfavorably to the use of a research-oriented topic.

An example of tasks in the ITS 340 research project included the creation of an interview to be conducted with a patient to retrieve general medical history information using a tree data structure. The project required a graphical user interface to display a question and retrieve input from a patient. Additionally, a graphical user-interface was developed to view, modify, add, and delete general medical history records. In contrast, the ITS 245 and CNIT 350 projects focused on developing a graphical user interface to a back-end database.

In the following analysis a "favorable" response means students that had selected either "Strongly Agree" or "Agree" in the survey. An "unfavorable" response means students had selected either "Strongly Disagree" or "Disagree". Specifically, the analysis for each research question is as follows:

\section{Q1: Did the research-oriented project topic increase their level of programming skills specific to the course?}

It can be seen from Table 2a that in the CNIT 350 - Object Oriented Programming course, 100\% of the students agreed. In ITS 245 - Integrative Programming it can be seen that 57.1\% responded favorably (see column 7, Table 2b) and in ITS 340 - Advanced Programming 83.3\% responded favorably. This supports using research-oriented topics in future class team projects since an overwhelming number of students thought that there was obvious value to them by the increase of their programming skills specific to the course content. The use of a specific research topic may have had a slight effect on student response since 100\% of CNIT 350 students, but only 57.1\% of ITS 245 students responded favorably. The differences are between the two courses with similar topics which may be related to the specific skills of the cohort of students in the respective courses.

Q2: Did the research-oriented project topic increase their level of programming skills more than other types of programming projects?

It was found that in CNIT 350 - Object Oriented Programming 92.9\% of the students surveyed (see column 7 corresponding to question 2 in Table 2a) responded positively ("Strongly Agree" or "Agree"). In ITS 245 - Integrative Programming only $14.3 \%$ of the students responded favorably (see column 7 corresponding to question 2 in Table $2 \mathrm{~b}$ ) even though the research-oriented topics were very similar between the two courses. However, $85.7 \%$ were neutral (see column 9, question 3, Table 2b). In ITS 340 - Advanced Programming 41.7\% of the students responded favorably (see column 7 corresponding to question 2 in Table $2 \mathrm{c}$ ). The use of a research-oriented topic required a more rigorous compliance to the requirements in the statement of work with more extensive input validation and testing than a regular course project. This may have contributed to student belief in CNIT 350 that this type of topic increased their level of programming skills more than other project topics. The great difference between ITS 245 and CNIT 350 to the answer to this question may be related to a difference in the readiness of students in the respective cohorts to do this type of work and that it may have been more difficult for students to understand how to do this in C\# rather than Java. However, this is a less likely explanation since both languages are similar. However, the $85.7 \%$ neutral response in ITS 245 and a $0 \%$ unfavorable response indicates that it was not a negative response, but some less enthusiastic response in the particular cohort of students. In the ITS340 course, the topic focused more on the use of a data structure to perform an interview which gathered data and stored it in the database with less emphasis on the user interface. Even though the implementation of a data structure to drive the interview was more technically challenging than 
implementing a user-interface, there was less overall coding once the data structure and process was coded which led to a higher positive support of this question than for ITS 245 which had a user-interface oriented topic.

\section{Q3: Do students prefer a research-oriented project topic to other topics?}

In CNIT 350 - Object Oriented Programming, 50\% of the students responded favorably. In ITS 245 - Integrative Programming, again only $14.3 \%$ of the students responded favorably and in ITS $34033.3 \%$ of the students responded favorably. The lack of overwhelming positive support to this question could be linked to the fact that the researchoriented topic was more rigorous and difficult to complete due to the requirement of strict adherence to requirements and quality of software. The use of a specific topic may have had an impact on the student responses between CNIT 350 and the topics in ITS 245 and 340 which had lower favorable responses.

\section{Q4: Do students prefer to have projects that contribute to a professor's on-going research?}

In CNIT 350 - Object Oriented Programming, 92.9\% of the students responded favorably (see column 7, question 4, Table 2a). In ITS 245 - Integrative Programming, 57.1\% of the students responded favorably (see column 7, question 4, Table 2b). In ITS 340 - Advanced Programming, 41.7\% of the students responded favorably (see column 7 , question 4, Table 2c). The majority of students either indicated that they "Strongly Agree" or "Agree" (see column 7, question 4, Table 2) that they prefer to have projects that contribute to a professor's on-going research. This response indicates that if the project they are working on may be an actual contribution to an on-going research project then it increases their preference for such a research-oriented project. The specific research-oriented topic may have had an impact on the student responses which were very favorable at $92.9 \%$ in CNIT 350, moderately favorable at $57.1 \%$ in ITS 245 , and less favorable at $41.7 \%$ in ITS 340 . Again, the complexity level of code (data structure programming) may have been found to be more complex by students than user-interface and database programming in CNIT 350 and ITS 245.

\section{Q5: Would students like to have other research-oriented topics in other courses?}

In CNIT 350 - Object Oriented Programming, 71.4\% of the students responded favorably (see column 7, question 5, Table 2a). In ITS 245 - Integrative Programming, 42.9\% responded favorably (see column 7, question 5, Table 2b). In ITS 340 - Advanced Programming, 33.3\% of the students responded favorably (see column 7, question 5, Table 2c). Overall, the responses to this question are mixed, in that 17 students between the three courses had a favorable response and 16 were either neutral or not favorable. Again, the cohort of students in the CNIT 350 course supported this more strongly than in the other courses. It is not clear why this cohort thought of this more favorably when they had a more neutral response to question 3. The ITS 340 course had a more difficult programming topic which may have contributed to their $33.3 \%$ favorability response.

Q6: As a result of doing a research-oriented topic in the course, would students like the opportunity to collaborate on an undergraduate information technology research project with a professor?

In CNIT 350 - Object Oriented Programming, 78.6\% of the students responded favorable (see column 7, question 6, Table 2a). In ITS 245 - Integrative Programming, 28.6\% responded favorably and $28.6 \%$ not favorably (see column 7, question 5, Table 2b). In ITS 340 - Advanced Programming, 41.7\% responded favorably and 41.7 were neutral (see column 7, question 5, Table 2c). Overall, there was no major negative response to this question. This supports that regardless of the project, students seemed to like or were neutral to doing something that appears to have a more tangible impact rather than a project which will never be used outside the course. There appears that there may have been an impact on the specific project in CNIT 350 which had a 78.6\% positive response and the significantly lower favorable responses of $28.6 \%$ in ITS 245 and $41.7 \%$ in ITS 340.

Q7: As a result of having exposure to a research-oriented topic in the course project, would students be motivated to go to graduate school? 
In CNIT 350 - Object Oriented Programming, 21.4\% of the students responded favorably and 57\% were neutral (see column 7, question 7, Table 2a). In ITS 245 - Integrative Programming, 14.3\% responded favorably and $42.9 \%$ were neutral (see column 7, question 7, Table 2b). In IT 340 - Advanced Programming, 8.3\% responded favorably and $50 \%$ were neutral (see column 7, question 7, Table 2c). In this question, it was found that there was a small number of students that found that doing research-oriented topics in courses would motivate them to go to graduate school. The majority were neutral. Therefore, the specific research-oriented topic had no effect on the decision whether to go to graduate school.

Q8: As a result of having exposure to a research-oriented course topic, would students like the opportunity to do more undergraduate research through independent study courses?

In CNIT 350 - Object Oriented Programming, 57.1\% responded favorably and 42.9\% were neutral (see columns 7 and 9, question 8, Table 2a). In ITS 245 - Integrative Programming, the responses were $28.6 \%$ favorable, neutral and not favorable (see columns 7, 8 and 9, question 8, Table 2b). In ITS 340 - Advanced Programming, 16.7\% were favorable, and 58.3\% were neutral (see columns 7 and 9, question 8, Table 2c). The use of a specific research-oriented topic may have had some effect on the research topic since CNIT 350 had 52.4\% seeing it favorable that they would like to do more research through independent study while only $16.7 \%$ of students in ITS 245 saw this as favorable. ITS 245 was neutral. The result may be due to the topic differences in that ITS 340 had a lot of complexity to the writing data structures code while CNIT 350 had more straight forward user-interface programming. This may have contributed to ITS 340 students believing that most were at their limit of complexity on this type of task.

Q9: Do students perceive that having some undergraduate research-oriented experience have a positive impact on getting a job after graduation?

In CNIT 350 - Object Oriented Programming, 100\% responded favorably (see column 7, question 9, Table 2a). In ITS 245 - Integrative Programming, 71.4\% responded favorably (see column 7, question 9, Table 2b). In ITS 340 Advanced Programming, 75\% responded favorably. The use of a specific research-oriented topic did not have an effect on a favorable response to having research-oriented topics having a positive impact on getting a job after graduation since there were an overwhelming number of students that responded favorably across all the courses.

Q10: Did doing a research-oriented project in the course enhance your undergraduate experience?

In CNIT 350 - Object Oriented Programming, 100\% of students responded favorably (see column 7, question 10, Table 2a). In ITS 245 - Integrative Programming, 42.9\% had favorable responses and 42.9\% were neutral (see columns 7 and 9, question 10, Table 2b). In ITS 340 - Advanced Programming, 50\% responded favorably and $41.7 \%$ were neutral (see columns 7 and 9, question 10, Table 2c). The use of specific research-oriented topics may have had an impact on whether having a research-oriented topic enhanced students' undergraduate experience since CNIT 350 had a $81 \%$ favorable response whereas the other two courses were generally neutral.

\section{Grade Analysis}

The survey was distributed to each student before grades on the research-oriented projects were assigned. The percentage scores for each student's course project that used a research-oriented topic in the spring 2017 CNIT 350 Object-Oriented Programming course, fall 2017 ITS 245 Integrative Programming course and spring ITS 340 course are shown in Table 3.

There were a total of 42 students in the three courses. The average project score for all student in CNIT 350 - Object Oriented Programming was $82.4 \%$, in ITS 245 - Integrative Programming was $75.5 \%$, and in ITS 340 - Advanced Programming was $94.8 \%$ as shown in Table 3.

There was no clear, consistent correlation between the responses and grades on the specific research-oriented topics in each of the courses. While the average positive response was the highest in the CNIT 350 course with a score of $66.4 \%$ (see column 7, avg, Table 2a), the project score was not the highest between the three courses at $82.4 \%$. While the ITS 340 course had the highest score in the research-oriented topic project at $94.8 \%$, the average positive response 
was $42.5 \%$ (see column 7, avg, Table 2c). The ITS 245 course had the only consistent relationship between having the lowest average score for the projects at $75.5 \%$ and the lowest average positive response to all the questions at $37.2 \%$. Therefore, there was no clear correlation between the average grade scores for the students in the course and their average positive responses to the questionnaire.

The grade analysis was also done to see if grades improved if students were more motivated when working on a research-oriented topic that had the potential to be integrated into an existing research project. The grade analysis does not support this, but it is unclear if there were other variables that affected the scores as discussed above.

\section{CONCLUSIONS AND FUTURE WORK}

Based on the aforementioned discussion, it can be concluded that there may be some correlation between specific research-oriented topics and positive responses to the survey questions:

- Question 1: Did the research-oriented project topic increase their level of programming skills specific to the course? The use of a specific research topic may have had a slight effect on student response since $100 \%$ of CNIT 350 students, but only $57.1 \%$ of ITS 245 students responded favorably. The differences are between the two courses with similar topics which may be related to the specific skills of the cohort of students in the respective courses.

- Question 2: Did the research-oriented project topic increase their level of programming skills more than other types of programming projects? The use of a specific research topic may have had an effect on student response since $92.9 \%$ of CNIT 350 students, but only $14.3 \%$ of ITS 245 students and $41.7 \%$ of ITS 340 students responded favorably.

- Question 4: Do students prefer to have projects that contribute to a professor's on-going research? The specific research-oriented topic may have had a slight impact on the student responses which were very favorable at $92.9 \%$ in CNIT 350, moderately favorable at $57.1 \%$ in ITS 245, and less favorable at $41.7 \%$ in ITS 340.

- Question 5: Would students like to have other research-oriented topics in other courses? The specific researchoriented topic may have had an impact on the student responses which were favorable at $71.4 \%$ in CNIT 350 , $42.9 \%$ in ITS 245 , and $33.3 \%$ in ITS 340 .

- Question 6: As a result of doing a research-oriented topic in the course, would students like the opportunity to collaborate on an undergraduate information technology research project with a professor? There appears that there may have been an impact on the specific project in CNIT 350 which had a $78.6 \%$ positive response and the significantly lower favorable responses of $28.6 \%$ in ITS 245 and $41.7 \%$ in ITS 340.

- Question 8: As a result of having exposure to a research-oriented course topic, would students like the opportunity to do more undergraduate research through independent study courses? The use of a specific research-oriented topic may have had some effect on the research topic since CNIT 350 had $52.4 \%$ seeing it favorable that they would like to do more research through independent study while only $16.7 \%$ of students in ITS 245 saw this as favorable.

- Question 10: Did doing a research-oriented project in the course enhance your undergraduate experience? The use of specific research-oriented topics may have had an impact on whether having a research-oriented topic enhanced students' undergraduate experience since CNIT 350 had a $81 \%$ favorable response whereas the other two courses were generally neutral.

Care must be taken in selecting research-oriented topics that correlate to course topics and student skills. Differences in topics may have an impact on student views related to the benefit of such topics related to increasing their programming skills, their interest in research, their undergraduate experience and ultimately whether they pursue a graduate education. This study has compared three different research-oriented topics introduced into three different undergraduate courses and has found that there may be an impact on student favorable views to questions as posed in the survey depending on the research topic being done by the students. The study was small over three courses, three topics and 42 students. Future work will need to increase the number of students participating in such topics and increase in the number of different topics to try to see what variables in the topics might have the most negative impact. 


\section{Issues in Information Systems}

Volume 19, Issue 4, pp. 53-64, 2018

Also, an additional study should be performed to determine the impact of a particular programming language, C\# vs Java, on the number of required tasks in the statement of work that are completed successfully in each particular language and the overall influence of the language on the student grade for the project.

\section{REFERENCES}

Elton, L. (2006). The nature of effective or exemplary teaching in an environment that emphasizes strong research and teaching links. New Directions for Teaching and Learning, 107, 33-41.

Fechheimer, M., Webber, K., \& Kleiber, P. B. (2011). How well do undergraduate research programs promote engagement and success of students?. CBE-Life Sciences Education, 10(2), 156-163.

Gates, A. Q., Teller, P. J., Bernat, A., Delgado, N., \& Della-Piana, C. K. (1999). Expanding participation in undergraduate research using the affinity group model. Journal of Engineering Education, 88(4), 409-414.

Hathaway, R. S., Nagda, B. A., \& Gregerman, S. R. (2002). The relationship of undergraduate research participation to graduate and professional education pursuit: an empirical study. Journal of College Student Development, 43(5), 614-631.

Kuh, G. D. (2008). Excerpt from high-impact educational practices: What they are, who has access to them, and why they matter. Association of American Colleges and Universities.

Russell, S. H., Hancock, M. P., \& McCullough, J. (2007). Benefits of undergraduate research experiences. Science (Washington), 316(5824), 548-549.

Schneider, K. R., Bahr, D., Burkett, S., Lusth, J. C., Pressley, S., \& VanBennekom, N. (2016). Jump starting research: Preresearch STEM programs. Journal of College Science Teaching, 45(5), 13-19.

Stefanek, G. \& Desai, N. (2018, June). Integration of Research Topics into Undergraduate Information Technology Courses and Projects. In Proceedings of the 2018 ASEE Annual Conference \& Exposition.

Varde, K. S. (2005). Energy and Engines Research through Undergraduate Research Program. In Proceedings of ASEE Annual Conf. and Expo. 